\title{
A left \\ communitarianism? \\ What about \\ multiculturalism?
}

\section{Tariq Modood and Jan Dobbernack}

\section{A more plural approach can help to heal breaches both within the 'multicultural community' and beyond.}

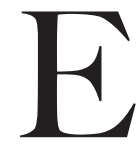

jected from power, the centre left is once again a place of thinking. Old antagonisms that marked the ways in which its fractions conceived of

culture, identity, difference and equality are being reconsidered. Recent

discussions that put at the centre of debate issues of cultural politics and social renewal - rather than the management of markets, public services and the state - are very much to be welcomed. In the debate, traditions and concerns of the working class, especially in relation to identity-anxieties, have become key matters. We welcome this focus but worry that minority-majority relations are not featuring in it. This dimension, for example, was entirely missing from a recent ideological mapping by Stuart White that put figures such as Jon Cruddas and Jonathan Rutherford into the 'left communitarian' corner. ${ }^{1}$ Admittedly it was a very short piece, but it baffles us that anyone can outline 'four evolving strands of progressive thought' without any reference to the place of minorities and 'difference' (including gender) in these positions. Rethinking progressive politics should be about more than marrying white working-class organisations and white middle-class intellectuals. 


\section{A left communitarianism?}

The new thinking must include multiculturalism, but that is not the point that we are rehearsing now. ${ }^{2}$ Rather, in recognition that this is a time to bring together the fragments of the alternative to the right, and to get beyond some of our divisions, we are attempting to do this in a specific case. Our argument is that there has been a major division in what we might call the multicultural constituency, and that now is a time to lessen the breach. At the same time we think that our efforts speak to the new debate that recent articles in Soundings have been addressing, which, interestingly, have some real parallels with the division amongst multiculturalists. ${ }^{3}$

\section{Two modes of 'difference'}

Let us start with lived experience. It is almost too obvious to mention that to speak of British ethnic diversity is not to speak of a variety within a single register. There are differences in kind in how non-white Britons conceive of themselves, their place in the world, and their identities and relationship with society and with others. For some the legacies and hurts of colour racism are central; for others it may be national origins or cultural-linguistic heritages; for others the call of faith or the voices of a global faith community cannot be ignored. For many, especially younger people, the predicament and the opportunity of hybridity fascinate. Progressives have embraced the sociability of the intercultural - welcoming challenges to tradition, and to the authority of boundaries, indeed the very fact of novelty - but have been divided when religious communities have sought national recognition, political representation and legal dispensation. So, when Cameron proclaims that he is against 'state multiculturalism' he is denounced by progressives for ignoring the fact there are many happy multiethnic neighbourhoods - as if his problem is discomfort with a home in multicultural Notting Hill. Yet, for many progressives, no less than for Cameron, state endorsed communitarian multiculturalism is the problem. Leaving aside the role of the state on this occasion, there remains the problem that the centre left is distinctly unenthusiastic about groups whose 'difference' lies in community rootedness, especially if religious and demanding in public. Till we find a way of bridging these two modes of 'difference' - the fluidly hybridic and the communally conserving - there can be no satisfactory political response to anti-multiculturalism.

Each of these two modes of 'difference' projects their own version of multicultural 


\section{Soundings}

society. The first, which we will call multiculturalism, is in favour of public spaces that allow for, refrain from penalising, and ideally respect, the simultaneous assertion of claims for difference and inclusion. It thus responds to attempts by post-immigration groups to maintain ideas and practices, or to change them in a way that preserves the core of what is considered valuable. Its goal is to transform the public sphere in order to turn negative into positive difference, and to allow, for example, for the expression of religious beliefs and the accommodation of religious practices in the public realm, rather than their confinement within the private sphere.

Multiculturalism articulates the value of cultural pluralism. In contrast to its caricatures, it attempts to show that pluralism need not lead to mutual animosity but is consistent with dialogue and engagement. Multiculturalism suggests consideration for the ethnic or religious identities that are empirically present in Britain, and respect for the value they hold for their bearers. This does not imply uncritical respect or unreserved admiration. Rather, its call is for engagement, contact and consideration, rather than the knee-jerk exclusion from the public sphere that is too often the order of the day, and which, in turn, makes the minorities that protest against it seem like trouble-makers.

The second version of a multicultural society, which we call multiculture, has been coined in relation to situations of everyday cultural and ethnic diversity, conviviality and particularly the Black-Caribbean experience. Its domain lies in moments of contact, mixing and cultural exchange - often within, but not restricted to, urban settings. It speaks of the hybridisation of culture and the creation of spaces that allow for relatively effortless encounters. Its ethical core is the creative adaptation of culture under conditions of uncertainty and crisis. As Kobena Mercer says: 'In a world in which everyone's identity has been thrown into question the mixing and fusion of disparate elements to create new, hybridized identities points to ways of surviving, and thriving, in conditions of crisis and transition'. ${ }^{4}$

The possibilities that come from practices of hybridity consist in the dissolution of settled certainties on the side of minority and majority groups. From the mould of urban life new practices and forms of social life emerge that challenge monocultural conceptions and pure identities. Multiculture, on this account, entails ethical resistance to imposed homogeneity and racialised certainty. It foregrounds the emergence of new cultural forms in which individuals re-make themselves, thus exposing the hollowness of inherited identities. In some of the ways it has been defined for political purposes, it 


\section{A left communitarianism?}

is openness and 'the unknown' that is emphasised. Rather than being concerned with 'being', with the presence of difference, it focuses on 'becoming' and the possibilities of future and as yet 'unknowable' identities, which need to be politically accommodated - and whose emergence needs to be facilitated.

Each disposition makes sense in relation to some but not other situations and experiences. And these two modes are not distributed evenly across groups: one can be more characteristic of one group, and the other of another group. Moreover, each disposition can be present in the different ways in which even a single person conceives of his or her place in the world; an individual can be drawn to both ways of living. These sensibilities speak to distinct goods, that can be justified with reference to the purposes they serve as well as to the value they possess. The unsettling of stable and homogeneous identities contributes to the effort of making societies hospitable to post-immigration groups and individuals; while the maintaining and re-making of community - the disposition of multiculturalism - offers something that is not solely of value to members of the minority community in question, but can be a source of new social horizons.

\section{Either-Or?}

In British politics in the last two decades or so, even in the period before the furore surrounding Salman Rushdie's Satanic Verses, various contested events and public disputes have been driven by antagonism between the two modes of 'difference'. Such conflicts may be serious and do require careful consideration. They are, however, misrepresented when they are seen to be fuelled by the antagonism of binary opposites; when two ways of conceiving of difference are pitted against each other as if in some existential opposition; and when the resolution to the alleged antagonisms involves banishing one side, which is seen to be distorted, inauthentic and dangerous. This forecloses dialogue and makes it harder to arrive at shared political positions - which is unfortunate for many reasons, not least inasmuch as the political priorities of anti-discrimination, anti-racism and equality are, more frequently than not, widely shared. The Rushdie Affair is a classic example: the labels of, on the one hand, 'cultural traitor', 'brown sahib' and 'coconut', and, on the other, 'fundamentalist', 'fanatic' and 'mad mullah', were hurled between co-ethnics and co-religionists as well in wider circles. 


\section{Soundings}

Such antagonisms are not confined solely to the passions of the street, and have had considerable influence in scholarly debates. Claire Alexander, for example, has criticised the consideration of difference in multiculturalism. She takes issue with the movement towards what she considers the "too easy valorisation of an increasingly inward-looking and (apparently) self-defining "difference". ${ }^{5}$ This, she suggests, involves 'the erection of seemingly insurmountable boundaries between Britain's African, Caribbean and Asian communities', which she declares to be 'empirically unsustainable'. Alexander chooses here to minimise dissimilarities, such as the differential significance of religion among British post-immigration groups, and to overplay the impossibility of relationships despite differences. She laments the creation of new boundaries, but is unable to articulate ways in which these could be overcome without subduing the one position that she considers undesirable. In fact, in affirming dichotomous pairings - and merely disputing their empirical reality - she does little if anything to help us move towards a shared agenda for British postimmigration groups.

Alexander is not alone in her repudiation of one kind of difference. For some writers, inasmuch as ethno-religious and group-based identities are considered at all, they are frequently rejected as undesirable; such writers tend to regard ethnic and religious identities as anachronistic expressions, out of touch with the realities of diasporic life. This binarism is given expression by John Solomos and Les Back, who, in summing up the scholarly literature post-Satanic Verses, speak of a choice between 'either embracing the complex multiple formation of itinerant culture produced through movement and passage; or the assertion of arborescent traditions that in one way or another rely upon the simplicity of racial and cultural essences'. ${ }^{6}$

Jeremy Waldron, also writing in response to the Satanic Verses affair, speaks of a tension between the 'one culture' and the 'many cultures' model. ${ }^{7}$ For Waldron, 'many cultures' and the 'fragmented self' are characteristic of the experience of post-immigration diaspora. The diasporic condition can barely be conceived of without an account of fragmented identities and pluralised difference. From a different perspective, Paul Gilroy rejects the 'deep desire for mechanical solidarity, seriality, and hypersimilarity' - a desire he appears to find in the types of communal identifications that he dislikes. ${ }^{8}$

There are notable alternatives and a number of accounts that attempt to bridge the divide, such as the report of the Commission for Multi-Ethnic Britain (CMEB), 


\section{A left communitarianism?}

also known as The Parekh Report. The CMEB saw the idea of a 'community of communities and individuals' as undergirded by a human rights framework and by government commitment to substantially decreasing the scale of socio-economic inequalities current in Britain. ${ }^{9}$ It highlighted the existence of newer and multiple racisms, and put emphasis on identifying and eliminating these. It acknowledged tensions, such as between the 'liberal' and the 'pluralist' accounts: 'citizens are not only individuals but also members of particular religious, ethnic, cultural and regional communities, which are comparatively stable as well as open and fluid. Britain is both a community of citizens and a community of communities' ( $p$ xi and para 4.19). This formulation allows for the possibility of simultaneously contesting notions of homogeneous nationhood and articulating claims for dignity and respect. These two sensibilities do not need to be at odds.

\section{Speaking across 'difference'}

When one way of conceiving of difference is made universal, in spite of all that is contradicting and incongruous in the various realities of multicultural Britain, it is not surprising that its adherents are inclined to conceive of divergent experiences as aberrant, inarticulate or dangerous. Narrow and univocal conceptions of culture and cultural politics, however attractive in themselves, are exclusionary. Given the variety of multicultural experiences, we should be interested in encounters that require neither exclusion nor reduction.

Rejecting exclusion and antagonism and merely enumerating the plurality of perspectives only gets us so far however. We need to be concerned with encounters, relationships and interaction. After all, the challenge of antagonism is its rejection of such possibilities. Contributions to social theory have made a number of suggestions about the ways in which communicative relationships across differences in society should be considered. Here we explore translation, dialogue and conversation. We suggest that all three indicate particular understandings of encounters, and all have their place and virtues.

Translation is at the core of Jürgen Habermas's recent 'post-secular' revision. Habermas uses the notion of translation to carve out a less marginal place for religion in modern, 'post-metaphysical' societies. To cut a complicated story short, our view is that the kind of translation that Habermas propagates may not serve its 


\section{Soundings}

intended purpose. Secular language can extract meaning from the religious, but for Habermas it must be clinically done, with avoidance of contamination. His approach to translation is somewhat unidirectional, fixated on religion as a problem sui generis, and is thereby at risk of undermining a disposition towards understanding. It is at odds with the epistemological non-authoritarianism that could play a vital role for the purposes of social integration, solidarity, and civic engagement - purposes that Habermas values highly in his concern with the 'pre-political foundations' of the democratic-constitutional state.

There can be an understanding of translation that resonates strongly with the idea of multicultural hybridity. Homi Bhabha suggests that in the translation process meaning is transformed and dissolved. Translation involves the "movement of meaning' in both directions of the translation act: 'the content or subject matter [of what is being translated] is made disjunct, overwhelmed and alienated'. ${ }^{10}$ When two kinds of difference encounter each other in this way, both are transformed and unsettled, and neither remains as it was. While this is a corrective to Habermas's idea of translation as unidirectional, it still falls short of what we may expect. It has no account of how or why certain subjectivities may refuse to be unsettled in the translation process - may insist on their perspective and maintain their worth - and should not be condemned for doing so.

Where translation falls short, dialogue may present itself as an alternative. Bhikhu Parekh is an exponent of the idea of multicultural dialogue. For Parekh, dialogue indicates a way towards understanding, and towards a common framework that conceives of the plurality of perspectives as something positive - not as an impediment but as an opportunity for self-improvement and collective learning. Parekh defines dialogue 'widely' - 'to mean not only talking and persuading but also negotiating and reaching a compromise'; ${ }^{11}$ he sees it as a process with a 'transformative effect', where there is the possibility for human beings to 'experiment with different ideals, values and forms of life, develop newer forms of diversity, and enrich others with their unique contributions' (p277). With this commitment Parekh locates his understanding of dialogue in a tradition of philosophical hermeneutics, where the particularity of positions and perspectives is reconciled with an ethical posture towards the other.

Two-way translation and dialogue are appropriate and necessary ways of identifying and extending commonalities, and essential for co-operation and 


\section{A left communitarianism?}

coalition-building. This is the case with each of the modes of 'difference' we have identified - both for transgressive cosmopolitans and ethno-religious communities. Yet perhaps the claim that no identity is equivalent to that achieved in Islam will for the former always be 'fundamentalism'; while to the latter the cosmopolitan may always lack integrity and dignity. For such persons, or at least in relation to certain aspects of these persons, we need something better than disgust, offensiveness or sullen silence. For this we may adapt an idea from Michael Oakeshott. In his idea of a 'conversation of mankind', Oakeshott offered an image of how different aspects of human thought, which were categorically apart and potential worlds unto themselves, might relate to each other. In placing aesthetic experience (or 'poetry' as he called it) alongside science, history and other similar disciplines, Oakeshott envisaged them as voices in conversation. The 'conversation of mankind' is:

... the meeting-place of various modes of imagining; and in this conversation there is, therefore, no voice without an idiom of its own: the voices are not divergencies from some ideal, non-idiomatic manner of speaking, they diverge only from one another. Consequently, to specify the idiom of one is to discern how it is distinguished from, and how it is related to the others. ${ }^{12}$

The important point here for our purpose is that a conversation is a form of discourse which is not premised on disciplinary uniformity. Participants in conversation do not impose singular standards upon other conversationalists but enjoy a moment away from their usual single-mindedness. This is a vision of a relationship between categorically different ways of being without hierarchy, antagonism, competition, assimilation or instrumentality, where there may not be perfect mutual understanding of the kind that exists between disciplinary colleagues, but where nevertheless there is a desire to converse across difference.

We want to borrow this image without claiming that Oakeshott would have approved. The relationship between multiculture and multiculturalism could be one of non-assimilation and non-competition. It could be a conversational relationship, and so offer the prospect of a kind of respect. As Oakeshott puts it, different modes may 'acknowledge each other and enjoy an oblique relationship which neither requires nor forecasts their being assimilated to one another' (pp198-199). The kind of acknowledgement or respect that can be achieved can perhaps be characterised as 


\section{Soundings}

'I don't want to be like that but I value that others do'. ${ }^{13}$

In political terms, the challenge is to reach out for positions that are sensitive to ethnic difference and incorporate a respect for persons as individuals and for the collectivities to which people have a sense of belonging. That means a multiculturalism that is happy with hybridity but has a space for religious identities. Both 'hybridity' and ethno-religious communities have legitimate claims; they should not be pitted against each other in an either-or fashion, as is done all too frequently. They neither require reconciliation nor dissolution, but, rather, the acknowledgment that difference - as different modes of viewing oneself socially and culturally - does not foreclose a sense of mutual appreciation.

\section{Two sensibilities in culture and politics}

What is of particular interest here is that our two modes of 'difference' parallel what has been identified as the core antagonism that the centre left has to think with. Jonathan Rutherford locates it in the current cultural landscape. Amongst the 'educated elite' he sees an 'affirmation of racial and cultural difference, and a celebration of novel experience and the expanding of economic choice'. On the other hand, 'across the country a more conservative culture holds sway which values identity and belonging in the local and the familiar'. ${ }^{14}$ He goes on to argue, as we do, that these 'two cultural sensibilities of cosmopolitanism and conservatism need not be mutually exclusive'. Similarly, for Maurice Glasman the radical tradition is 'as committed to the preservation of meaning and status as it is to democratic egalitarian change, and seeks to pursue both'. ${ }^{15}$ What we are saying about translation, dialogue and conversation may have something to offer to this larger debate.

Such parallels suggest that the issues we have been discussing are not marginal, and we would like to conclude by insisting that the new communitarian thinking on the left, in its discomfort with an over-emphasis on difference as opposed to commonalities, and on minorities and not majorities, must not ignore the multicultural. Historically it is by now a cliché that invocations of 'THE community', 'the common good', 'the nation', are all too often monistic in their orientation, and can easily lead to an intolerant nationalism or extreme right 'integralism', with its inevitable corollary of violations of minorities; and recourse to such ideas also leads to a more global 'Us' and 'Them', as in the neo-con 'clash of civilisations' discourse. 


\section{A left communitarianism?}

These tendencies are not absent from the current debate. ${ }^{16}$ It is important therefore that, in reviving the idea of 'the common good', progressives avoid reductive ideas of community and look to radical traditions such as those of the English Pluralists and guild socialists. The latter were suspicious of state corporatism, and wanted the state to recognise the complexity of civil society and the economy, arguing that power should be distributed across that complex. Suitably reinterpreted for our times and circumstances, such traditions are hospitable to multiculturalism. Moreover, the conservative sensibility that communitarians are seeking to rehabilitate will find itself echoed amongst some minorities, and can be the basis for a multiculturalism that is more capacious than the one offered by those for whom only change, novelty and transgression are of value.

Tariq Modood is the Director of the Research Centre for the Study of Ethnicity and Citizenship at Bristol University, and the author of many books, the most recent of which is Still Not Easy Being British: Struggles for a Multicultural Citizenship (Trentham 2010). He is co-founding editor of Ethnicities. Jan Dobbernack is a Research Assistant in the School of Sociology, Politics and International Studies at Bristol University.

\section{Notes}

1. Stuart White, 'An ideological map', New Statesman, 3 September 2009.

2. For more on this see Tariq Modood, 'A Defence of Multiculturalism', in Race, Identity and Belonging, L\&W 2008, (www.lwbooks.co.uk/ebooks/raceident.pdf) (first published in Soundings 29).

3. See Jonathan Rutherford, 'The future is conservative', Soundings 47; Maurice Glasman, 'Labour as a radical tradition', Soundings 46.

4. Kobena Mercer, Welcome to the Jungle: New Positions in Black Cultural Studies, Routledge 1994, pp4-5.

5. Claire Alexander, 'Beyond Black: Re-thinking the colour/culture divide', Ethnic and Racial Studies 25(4), 2002, p553.

6. John Solomos and Les Back, Racism and society, Macmillan 1996, p155 (emphasis added). 


\section{Soundings}

7. Jeremy Waldron, 'Multiculturalism and mélange', in R.K. Fullinwider (ed), Public Education in a Multicultural Society, Cambridge 1996, p116.

8. Paul Gilroy, Between camps: race, identity and nationalism at the end of the colour line, Allen Lane 2004, p104.

9. Commission on the Future of Multi-Ethnic Britain, The Future of MultiEthnic Britain, Runnymede Trust 2000, para 4.19.

10. Homi Bhabha, The location of culture, Routledge 1994, p323.

11. Bhikhu Parekh, A new politics of identity: political principles for an interdependent world, Palgrave Macmillan 2008, p165.

12. Michael Oakeshott, Rationalism in politics and other essays, Basic Books 1962, p206.

13. For example in the way that religious believers respect faiths they do not share or even fully understand. See Tariq Modood, 'Moderate secularism, religion as identity and respect for religion', The Political Quarterly 81(1), 2010.

14. 'The future is conservative', $\mathrm{p} 62$.

15. 'Labour as a radical tradition', p37.

16. See John Millbank, Christianity, the Enlightenment and Islam (especially the first half): www.abc.net.au/religion/articles/2010/08/24/2991778.htm; and, a partial self-corrective, Cameron on Islam, liberalism and multiculturalism: a brief comment: www.respublica.org.uk/blog/2011/02/cameron-islam-liberalism-andmulticulturalism-brief-comment. 


\section{Soundings is now freely available online to all subscribers}

Benefits include:

- Document to document linking using live references, for fast, reliable access to wider, related literature.

- Journal content that is fully searchable, across full text, abstracts, titles, TOCs and figures.

- Live links to and from major Abstract and Indexing resources to aid research.

- The ability to conduct full-text searching across multiple journals, giving you a wider view of the research that counts.

- Powerful TOC alerting services that keep you up to date with the latest research.

\section{Set up access now at:}

www.ingentaselect.com/register.htm

and follow the online instructions*

Subscription Enquiries: help@ingenta.com

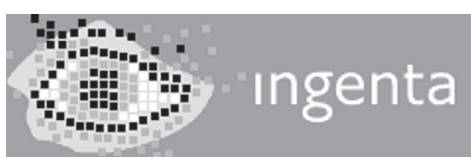

*Access is provided by Ingenta Select, an Ingenta website 